\title{
Phase II study of docetaxel and irinotecan combination chemotherapy in metastatic gastric carcinoma
}

\author{
SR Park', JH Chun', MS Yu', JH Lee', KW Ryu', IJ Choi', CG Kim', JS Lee', YW Kim', J-M Bae' and HK Kim*,I \\ 'Research Institute \& Hospital, National Cancer Center, 809 Madu I, Ilsan, Goyang, Gyeonggi 4 I0-769, Republic of Korea
}

\begin{abstract}
The current treatment for metastatic gastric cancer (MGC) consists of cisplatin and/or fluorouracil (5-FU) based combination chemotherapy, but cisplatin-based regimens are associated with considerable toxicity. We evaluated the efficacy and safety of a noncisplatin-, non-5-FU-containing regimen, docetaxel/irinotecan in MGC. Chemo-naive patients with MGC received docetaxel $\left(30 \mathrm{mg} \mathrm{m}^{-2}\right)$ and irinotecan $\left(70 \mathrm{mg} \mathrm{m}^{-2}\right.$ ) on days I and 8 every 3 weeks. The 48 eligible patients (median age 56 years) received a median of four cycles of docetaxel/irinotecan (range I-18). Of the 46 patients in whom efficacy could be evaluated, 21 showed a partial response (response rate $=45.7 \%$; $95 \%$ confidence interval $(\mathrm{Cl}) 31.3-60.1 \%$ ). At a median follow-up of 15.0 months, the median time to progression was 4.5 months $(95 \% \mathrm{Cl} 3.8-5.2$ months) and overall survival was 8.2 months (95\% Cl, $5.8-10.6$ months). Grade $3 / 4$ neutropenia developed in $57.4 \%$ of patients, and febrile neutropenia/neutropenic infection in $19.1 \%$. Nonhaematological toxicities were moderate; grade $3 / 4$ diarrhoea occurred in $19.1 \%$ of patients, however, was manageable by a dose reduction. There was one possible treatment-related death. In conclusion, weekly docetaxel/irinotecan is a promising outpatient regimen in MGC, with appropriate dose modification.
\end{abstract}

British Journal of Cancer (2006) 94, |402- |406. doi:I0.1038/sj.bjc.6603I 33 www.bjcancer.com

Published online 25 April 2006

(c) 2006 Cancer Research UK

Keywords: docetaxel; gastric cancer; irinotecan

Despite its decreasing incidence over the past few decades, gastric cancer remains one of the major causes of cancer deaths worldwide (Jemal et al, 2004) and is the most prevalent malignancy in Korea, constituting $24 \%$ of all solid tumours in males and $15 \%$ in females (Shin et al, 2004). Systemic chemotherapy is often used in patients with locally advanced or metastatic gastric cancer (MGC), but results of most combination regimens have been unsatisfactory, with median survival times of 6-9 months (Webb et al, 1997; Vanhoefer et al, 2000; Ohtsu et al, 2003). To data, the combination chemotherapies most commonly used have been based on fluorouracil (5-FU) and/or cisplatin, with 5-FU/cisplatin (FP) and epirubicin/cisplatin/5-FU currently regarded as reference treatment. However, cisplatin-based chemotherapy is associated with an unfavuorable toxicity profile, including severe emesis, neurotoxicity and nephrotoxicity. In addition, the need for intense intravenous (i.v.) hydration complicates the administration of this drug. Therefore, there is a need to develop active but less toxic chemotherapy regimens, which include new active compounds.

Docetaxel, which inhibits microtubule depolymerization, has been widely used in the treatment of MGC, with several phase II trials showing that this drug, as a single agent, induces response rates of 16-24\% (Sulkes et al, 1994; Bang et al, 2002). Moreover,

*Correspondence: Dr HK Kim, Gastric Cancer Branch, Research Institute and Hospital, National, Cancer Center, 809 Madul-dong, Ilsan-gu, Goyang-si, Gyeonggi-do 410-769, Republic of Korea.

E-mail: hkim@ncc.re.kr

Received 28 November 2005; revised 26 January 2006; accepted 31 March 2006; published online 25 April 2006 when combined with cisplatin, docetaxel has produced response rates of 33-56\% (Roth et al, 2000; Kettner et al, 2001; Ridwelski et al, 2001; Ajani et al, 2005).

Irinotecan, which inhibits topoisomerase I, thereby disrupting DNA replication, is a cytotoxic agent with promising activity. In MGC, irinotecan monotherapy has shown response rates of $20-$ 23\% (Futatsuki et al, 1994; Kohne et al, 2003) and irinotecan plus cisplatin has resulted in response rates of $32-58 \%$ (Ajani et al, 2002; Lim et al, 2003; Pozzo et al, 2004).

Given the activity of docetaxel and irinotecan in MGC and the different mechanisms of the two drugs, we designed a phase II trial to examine the efficacy and toxicity of this new combination in patients with MGC. As previous study of every-3-weeks docetaxel/ irinotecan in the chemo-naïve patients with advanced gastric cancer showed considerable toxicities, especially grade $3 / 4$ neutrpenia $(85.4 \%)$ and febrile neutropenia/neutropenic infection (41.4\%) (Hawkins et al, 2003), and both drugs are myelosuppressive, we administered each of these drugs once per week.

\section{PATIENTS AND METHODS}

\section{Patients}

Patients eligible for this trial were those aged over 18 years old with histologically proven gastric adenocarcinoma, metastatic disease, unidimensionally measurable disease, no prior chemotherapy including adjuvant chemotherapy, Eastern Cooperative Oncology Group (ECOG) performance status $0-2$, and adequate baseline hematological function (absolute neutrophil count $(A N C) \geqslant 1$. 
$5 \times 10^{9} 1^{-1}$, platelet count $\geqslant 100 \times 10^{9} 1^{-1}$ ), hepatic function (serum aspartate aminotransferase and alanine aminotransferase $\leqslant 2.5 \times$ the upper normal limit (UNL), serum bilirubin $\leqslant \mathrm{UNL}$ ) and renal function (serum creatinine $\leqslant \mathrm{UNL}$ ).

Patients were excluded if they had a history of other malignancies within the previous 3 years or pre-existing peripheral neuropathy of grade $\geqslant 2$ on the basis of the National Cancer Institute Common Toxicity Criteria (NCI CTC) (version 2.0). Written informed consent was obtained for all patients, and the institutional review board approved the protocol.

\section{Treatment}

Docetaxel $\left(30 \mathrm{mg} \mathrm{m}^{-2}\right)$ was administered as a 1-h i.v. infusion and irinotecan $\left(70 \mathrm{mg} \mathrm{m}^{-2}\right)$ as a 90 -min i.v. infusion on days 1 and 8 of each 3 -week cycle. Oral dexamethasone ( $8 \mathrm{mg}$ twice daily for six doses, starting $24 \mathrm{~h}$ before docetaxel) and parenteral pheniramine maleate $(45.5 \mathrm{mg})$ were administered prophylactically. Prophylactic administration of granulocyte-colony stimulating factor (G-CSF) was not allowed. The next chemotherapy cycle was delayed if ANC fell below $1.5 \times 10^{9} 1^{-1}$, the platelet count below $100 \times 10^{9} 1^{-1}$ or if patient experienced any other nonhaematological toxicity excluding alopecia greater than grade 1 . Doses of docetaxel and irinotecan were reduced by $20 \%$ in subsequent cycles if patients experienced grade 3 or 4 neutropenia with fever, grade 4 thrombocytopenia, or any grade $\geqslant 3$ nonhaematological toxicity. The dose of docetaxel was reduced by $20 \%$ in subsequent cycles if patients experienced grade 2 or 3 neurologic toxicity or recurrent fluid retention. The dose of irinotecan was reduced by 20 and $40 \%$ in patients experiencing grade 2 diarrhoea and 3 or 4 diarrhoea, respectively. Chemotherapy was administered on an outpatient basis and continued until disease progression or unacceptable toxicity developed.

\section{Assessment of efficacy and toxicity}

During the first two cycles, complete blood cell count and blood chemistry was performed weekly. In subsequent chemotherapy cycles, these tests were performed on days 1 and 8. A computed tomography (CT) scan was performed every three cycles to evaluate response to treatment. Complete response (CR), partial response $(\mathrm{PR})$, stable disease $(\mathrm{SD})$ and progressive disease $(\mathrm{PD})$ were defined according to the response evaluation criteria in solid tumour (RECIST) (Therasse et al, 2000). Responses were confirmed by an expert independent radiologist. Time to progression (TTP) was calculated from the date of first chemotherapy cycle to the date of disease progression, death from any cause, or last follow-up. Overall survival (OS) was calculated from the date of first chemotherapy cycle to the date of death from any cause or last follow-up. Toxicity was assessed before drug dosing using the NCI CTC (version 2.0).

\section{Statistical analysis}

The primary end point of this study was response rate. Secondary end points were TTP, OS and safety. The optimal Simon two-stage design was used to determine the sample size (Simon, 1989). An interim analysis was carried out when the first 15 assessable patients had been recruited. If there were four or fewer responses, the study was to be terminated. Otherwise, accrual was to be continued to a total of 46 patients. If there were more than 18 responses among 46 patients, the treatment was considered sufficiently active with a significance level of $5 \%$ and power of $80 \%$. TTP and OS were analysed according to the Kaplan-Meier method and updated to 30 August 2005.

\section{RESULTS}

\section{Patient characteristics}

From December 2003 to September 2004, 49 patients were enrolled in this study, $29(59.2 \%)$ males and $20(40.8 \%)$ females, of median age 56 years (range $29-72$ years). Most of the patients $(98.0 \%)$ had ECOG PS $0-1$, and $26(53.1 \%)$ had multiple metastases involving two or more organ systems. Metastatic sites were in the abdominal lymph nodes $(51.0 \%)$, peritoneum $(49.0 \%)$, liver $(36.7 \%)$, ovary $(12.2 \%)$ and others $(34.7 \%)$ (Table 1$)$. All patients had metastatic disease at diagnosis and two of them received palliative gastrectomy before the chemotherapy.

\section{Efficacy}

Of the 49 patients, 46 could be evaluated for response, whereas one was ineligible because of a previous history of cervical cancer and two were lost to follow-up prior to receiving three cycles of chemotherapy. According to the independent review panel, 21 patients (45.7\%) achieved confirmed PR, 15 (32.6\%) had SD and 10 (21.7\%) had PD. Thus, the overall response rate was $45.7 \%(95 \%$ confidence interval (CI) 31.3-60.1\%) (Table 2). All objective responses were confirmed by follow-up CT at least 4 weeks after the initial documentation of PR. The median duration of response was 4.8 months (range 1.8-11.5+ months). The median follow-up time was 15.0 months (range 11.6-21.0 months), during which the median TTP was 4.5 months (95\% CI 3.8-5.2 months) (Figure 1) and the median OS was 8.2 months (95\% CI 5.8-10.6 months)

Table I Patient characteristics

\begin{tabular}{lc}
\hline Characteristics & Number of patients (\%) \\
\hline Number of entered patients & 49 \\
Number of eligible patients & 48 \\
Age (years) & \\
Median & 56 \\
Range & $29-72$ \\
Gender & \\
Male & \\
Female & $29(59.2)$ \\
& $20(40.8)$ \\
ECOG performance status & \\
0 & \\
I & $3(6.1)$ \\
2 & $45(91.9)$ \\
Hiostology & $1(2.0)$ \\
Adenocarcinoma, well differentiated & \\
Adenocarcinoma, moderately differentiated & $2(4.1)$ \\
Adenocarcinoma, poorly differentiated & $14(28.6)$ \\
Signet ring cell carcinoma & $17(34.7)$ \\
& $16(32.6)$ \\
Metastatic organ sites & \\
Abdominal lymph node & \\
Peritoneum & $25(51.0)$ \\
Liver & $24(49.0)$ \\
Ovary & $18(36.7)$ \\
Others & $6(12.2)$ \\
Number of metastatic organ sites & $17(34.7)$ \\
I & \\
2 & \\
$\geqslant 3$ & $23(46.9)$ \\
\hline & $12(28.6)$ \\
& $12(24.5)$ \\
\hline
\end{tabular}

ECOG = Eastern Cooperative Oncology Group. ${ }^{a}$ Cervical lymph node, lung, bone, adrenal gland, uterus, gall bladder, pancreas. 
Table 2 Response to chemotherapy of 46 evaluable patients

\begin{tabular}{lc}
\hline Response & Number of patients (\%) \\
\hline Complete response & $0(0)$ \\
Partial response & $21(45.7)$ \\
Stable disease & $15(32.6)$ \\
Progressive disease & $10(21.7)$ \\
Overall response rate $(\%)^{\mathrm{a}}$ & 45.7 \\
$95 \% \mathrm{Cl}(\%)$ & $31.3-60.1$ \\
\hline
\end{tabular}

${ }^{a}$ Overall response $=$ complete response + partial response. $\mathrm{Cl}=$ confidence interval.

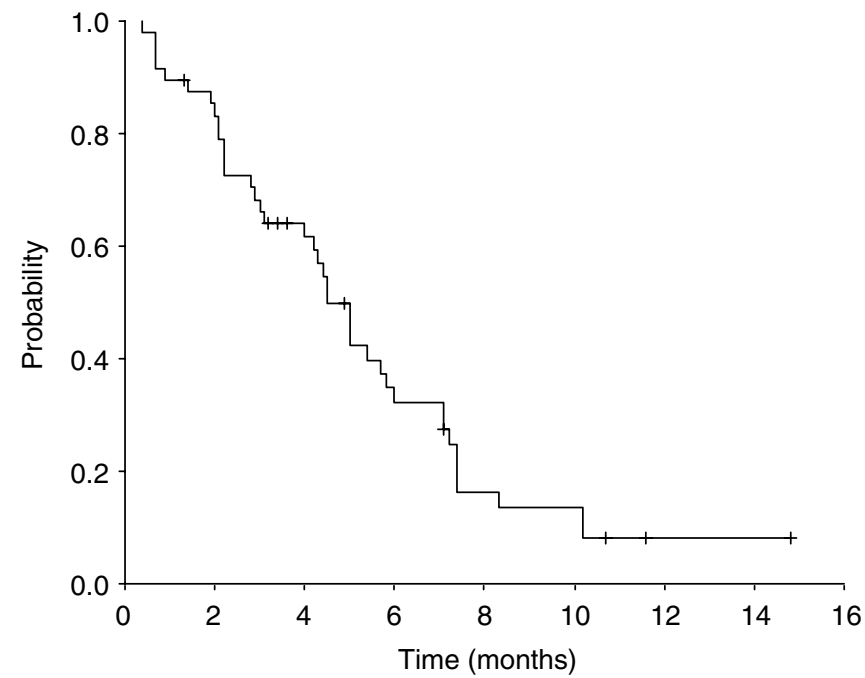

Figure I Time to progression for all eligible patients.

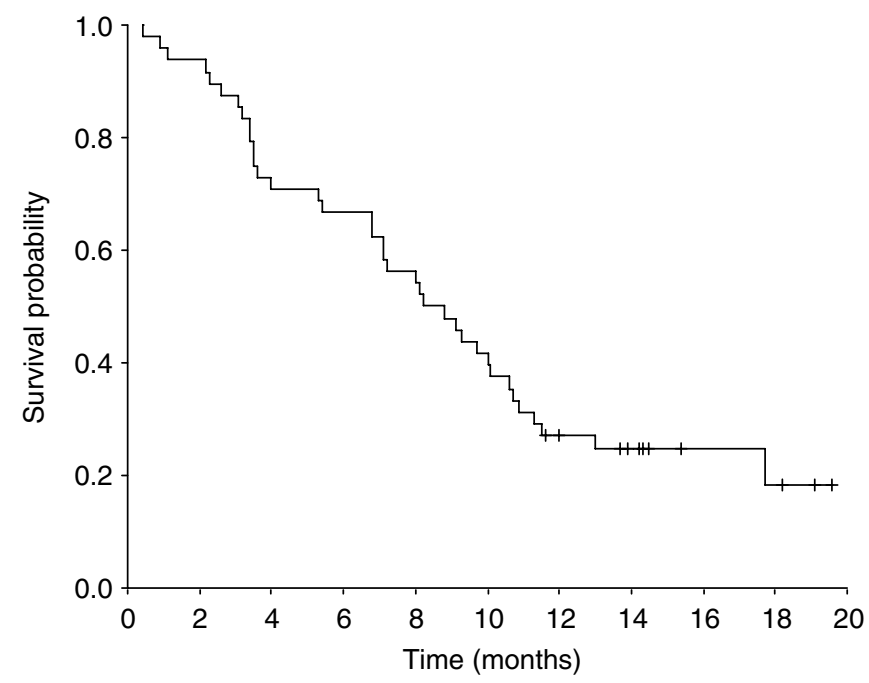

Figure 2 Overall survival for all eligible patients.

(Figure 2). The 1-year survival rate was $27.1 \%$ (95\% CI 14.6 $39.6 \%)$.

\section{Treatment delivered}

A total of 250 cycles were administered, with a median of 4 per patient (range 1-18). Treatment was delayed for a median of 6
Table 3 Toxicity of chemotherapy per patient $(n=47)$

\begin{tabular}{|c|c|c|c|c|}
\hline \multirow[b]{2}{*}{ Toxicity } & \multicolumn{4}{|c|}{ NCI-CTC Grade (\%) } \\
\hline & I & 2 & 3 & 4 \\
\hline \multicolumn{5}{|l|}{ Haematological } \\
\hline Leukopenia & $5(10.6)$ & I | (23.4) & $16(34.0)$ & $3(6.4)$ \\
\hline Neutropenia & $2(4.3)$ & $5(10.6)$ & $16(34.0)$ & II (23.4) \\
\hline Febrile neutropenia & - & - & $7(14.9)$ & $0(0)$ \\
\hline Thombocytopenia & $0(0)$ & $0(0)$ & I (2.1) & $0(0)$ \\
\hline Anaemia & II (23.4) & $27(57.4)$ & $7(\mid 4.9)$ & $0(0)$ \\
\hline \multicolumn{5}{|l|}{ Nonhaematological } \\
\hline Stomatitis & $14(29.8)$ & $8(17.0)$ & $3(6.4)$ & $0(0)$ \\
\hline Anorexia & $21(44.7)$ & $25(53.2)$ & $2(4.3)$ & $0(0)$ \\
\hline Nausea & $28(59.6)$ & $14(29.8)$ & $4(8.5)$ & - \\
\hline Vomiting & $12(25.5)$ & $21(44.7)$ & I (2.1) & $0(0)$ \\
\hline Diarrhea & $17(36.2)$ & II (23.4) & $7(\mid 4.9)$ & $2(4.3)$ \\
\hline Constipation & $17(36.2)$ & $3(6.4)$ & $0(0)$ & $0(0)$ \\
\hline Fatigue & $26(55.3)$ & $14(29.8)$ & I (2.1) & $0(0)$ \\
\hline Tearing & $4(8.5)$ & $0(0)$ & $0(0)$ & - \\
\hline Myalgia & I (2.1) & I (2.1) & $0(0)$ & $0(0)$ \\
\hline Alopecia & $21(44.7)$ & $23(48.9)$ & - & - \\
\hline Fluid retention & $8(17.0)$ & $6(12.8)$ & $0(0)$ & \\
\hline Peripheral neuropathy & $20(42.6)$ & I (2.1) & $0(0)$ & $0(0)$ \\
\hline Abnormal liver function & $12(25.5)$ & $4(8.5)$ & $0(0)$ & $0(0)$ \\
\hline Pneumonitis & $0(0)$ & I (2.1) & $0(0)$ & I $(2.1)$ \\
\hline \multicolumn{5}{|l|}{ Infection } \\
\hline With neutropenia & - & - & $3(6.4)$ & I (2.I) \\
\hline Without neutropenia & $0(0)$ & $0(0)$ & $5(10.6)$ & $0(0)$ \\
\hline
\end{tabular}

$\mathrm{NCl}-\mathrm{CTC}=$ National Cancer Institute Common Toxicity Criteria.

days (range $4-28$ days) in 31 cycles $(12.4 \%)$ in 21 patients $(43.8 \%)$, mainly because of febrile neutropenia/infection with neutropenia (seven cycles). Fourteen cycles were delayed due to reasons unrelated to disease or treatment, including pending imaging studies to evaluate response or the patient's request. Dose reduction was required in $126(52.4 \%)$ cycles in 26 patients (54.2\%), primarily due to diarrhoea (17 patients $(35.4 \%)$ ) and febrile neutropenia/infection with neutropenia (11 (22.9\%)). The relative dose intensities of docetaxel and irinotecan were $84.0 \%$ $\left(16.7 \mathrm{mg} \mathrm{m}^{-2}\right.$ per week) and $79.3 \%\left(37.0 \mathrm{mg} \mathrm{m}^{-2}\right.$ per week), respectively.

Of the 48 eligible patients, 35 (72.9\%) were discontinued due to disease progression, $2(4.2 \%)$ due to cerebral infarction, $1(2.1 \%)$ each for recurrent grade 3 diarrhoea, pulmonary embolism, gastric tumour bleeding and death. During the study, seven patients $(14.6 \%)$ withdrew their consent because of grade 1 or 2 fatigue $(n=4)$ and other reasons, including referral to other hospital $(n=1)$ and economic problem $(n=2)$.

\section{Toxicity}

Forty-seven patients were assessable for toxicity. Table 3 summarizes chemotherapy toxicities per patient. The most common haematological toxicity was neutropenia, which occurred at grade $3 / 4$ intensity in 27 patients $(57.4 \%)$. Febrile neutropenia occurred in seven patients $(14.9 \%)$ and infection with grade $3 / 4$ neutropenia in four patients $(8.5 \%)$. All of these patients were successfully treated with antibiotics and G-CSF. Grade 3/4 thrombocytopenia and anaemia occurred in one $(2.1 \%)$ and seven $(14.9 \%)$ patients, respectively.

Nonhaematological toxicities were mild to moderate and manageable. The most common grade $3 / 4$ nonhaematological toxicity was diarrhoea (19.1\%), followed by infection without neutropenia $(10.6 \%)$, nausea $(8.5 \%)$, stomatitis $(6.4 \%)$, anorexia 
(4.3\%), fatigue $(2.1 \%)$, vomiting $(2.1 \%)$ and docetaxel-induced pneumonitis $(2.1 \%)$. There was one $(2.1 \%)$ possible treatmentrelated death; this patient died at home of unknown causes 5 days after the last dose of chemotherapy in a cycle.

\section{Second-line chemotherapy}

During the follow-up period, 27 (56.3\%). of the 48 eligible patients received second-line chemotherapy, mostly containing cisplatin. Of the 27 patients, 15 received FP, six received capecitabine/ cisplatin, three received oxaliplatin/5-FU/leucovorin and three received other regimens. Of the efficacy-evaluable 23 patients, three $(13.0 \%)$ achieved PR, six (26.1\%) had SD and $14(60.9 \%)$ showed progression. The median TTP of second-line chemotherapy was 2.4 months (95\% CI 1.7-3.1 months).

\section{DISCUSSION}

We have shown here that weekly docetaxel in combination with weekly irinotecan is an active first-line chemotherapy regimen for MGC. The overall response rate of $45.7 \%$, median TTP of 4.5 months and OS of 8.2 months were comparable with previously published regimens, most of which are cisplatin-based. (Roth et al, 2000; Kettner et al, 2001; Ridwelski et al, 2001; Ajani et al, 2002; Lim et al, 2003; Pozzo et al, 2004; Ajani et al, 2005; Dank et al, 2005; Moiseyenko et al, 2005).

The administration of docetaxel-irinotecan every 3 weeks was performed as first-line chemotherapy for this disease with response rate of $37.5 \%$ (Hawkins et al, 2003). Although our weekly regimen showed lower incidence of grade $3 / 4$ toxicities than triweekly regimen (neutropenia 57.4 vs $85.4 \%$, febrile neutropenia/ infection with neutropenia 23.4 vs $41.4 \%$, and diarrhoea 19.1 vs $42.9 \%$ ), its toxicity should be generally considered significant.
Cisplatin-containing regimens have shown grade $3 / 4$ neutropenia, febrile neutropenia/infection with neutropenia and diarrhoea in $27-87 \%, 2-30 \%$ and $5-22 \%$ of patients, according to the published literature. On the other hand, compared with cisplatin-containing regimens, docetaxel/irinotecan combination was associated with a lower incidence of grade 2 or higher neurotoxicity (2.1 vs $2.0-30.8 \%)$ and all grade ototoxicity (0 vs 52.7\%) (Roth et al, 2000; Kettner et al, 2001; Ridwelski et al, 2001; Ajani et al, 2002; Lim et al, 2003; Pozzo et al, 2004; Ajani et al, 2005; Dank et al, 2005; Moiseyenko et al, 2005). In addition, this regimen did not resulted in any grade of nephrotoxicity.

Notably, this weekly regimen involved frequent dose reduction, especially of irinotecan, primarily due to diarrhoea, which occurred mainly in the first 1-3 cycles of therapy and was hardly repeated subsequently after a dose reduction. So, we would propose that the recommended irinotecan dose of this weekly regimen be lowered from 70 to $60 \mathrm{mg} \mathrm{m}^{-2}$, and that this regimen should be given only to patients with good performance status without any comorbidities. Yet, this weekly regimen allowed us to better modify subsequent drug dose and better manage drug toxicity with at least comparable therapeutic efficacy, compared with tri-weekly regimen. Taken together, we conclude that weekly docetaxel and irinotecan combination chemotherapy is a promising outpatient regimen in MGC, with appropriate dose modifications.

\section{ACKNOWLEDGEMENTS}

This trial was funded by National Cancer Center Grant 02-100-702. Docetaxel was in part provided by Sanofi Aventis Pharma Korea. This work was presented in part as a poster at the 2005 American Society of Clinical Oncology Gastrointestinal Cancers Symposium.

\section{REFERENCES}

Ajani JA, Baker J, Pisters PW, Ho L, Mansfield PF, Feig BW, Charnsangavej C (2002) CPT-11 plus cisplatin in patients with advanced, untreated gastric or gastroesophageal junction carcinoma: results of a phase II study. Cancer 94: $641-646$

Ajani JA, Fodor MB, Tjulandin SA, Moiseyenko VM, Chao Y, Cabral Filho S, Majlis A, Assadourian S, Van Cutsem E (2005) Phase II multiinstitutional randomized trial of docetaxel plus cisplatin with or without fluorouracil in patients with untreated, advanced gastric, or gastroesophageal adenocarcinoma. J Clin Oncol 23: 5660-5667

Bang YJ, Kang WK, Kang YK, Kim HC, Jacques C, Zuber E, Daglish B, Boudraa Y, Kim WS, Heo DS, Kim NK (2002) Docetaxel $75 \mathrm{mg} / \mathrm{m}^{2}$ is active and well tolerated in patients with metastatic or recurrent gastric cancer: a phase II trial. Jpn J Clin Oncol 32: 248-254

Dank M, Zaluski J, Barone C, Valvere V, Peschel C, Wenczl M, Goker E, Risse M, Awad L, Bugatet R (2005) Randomized phase 3 trial of irinotecan $(\mathrm{CPT}-11)+5-\mathrm{FU} /$ folinic acid (FA) vs CDDP+5-FU in 1st-line advanced gastric cancer patients. Proc Am Soc Clin Oncol 23: 308s (abstract no. 4003)

Futatsuki K, Wakui A, Nakao I, Sakata Y, Kambe M, Shimada Y, Yoshino M, Taguchi T, Ogawa N (1994) Late phase II study of irinotecan hydrochloride (CPT-11) in advanced gastric cancer. CPT-11 Gastrointestinal Cancer Study Group. Gan To Kagaku Ryoho 21: 1033-1038

Hawkins R, Cunningham D, Soerbye H, Adenis A, Canon J-L, LopezVivanco G, Jacques C, Stenger P, Zuber E, Misset J-L (2003) Randomized phase II trial of docetaxel plus irinotecan versus docetaxel plus 5-fluorouracil (5FU) in patients with untreated advanced gastric adenocarcinoma (AGAC). Proc Am Soc Clin Oncol 22: 257 (abstract no. 1032)

Jemal A, Tiwari RC, Murray T, Ghafoor A, Samuels A, Ward E, Feuer EJ, Thun MJ, American Cancer Society (2004) Cancer statistics, 2004. CA Cancer J Clin 54: 8-29

Kettner E, Ridwelski K, Keilholz U, Gallkowski U, Gebauer T, Kröning H, Eichelmann K, Fahlke J, Lippert H (2001) Docetaxel and cisplatin combination chemotherapy for advanced gastric cancer: Results of two phase II studies. Proc Am Soc Clin Oncol 20: 165 (abstract no. 657)

Kohne CH, Catane R, Klein B, Ducreux M, Thuss-Patience P, Niederle N, Gips M, Preusser P, Knuth A, Clemens M, Bugat R, Figer I, Shani A, Fages B, Di Betta D, Jacques C, Wilke HJ (2003) Irinotecan is active in chemonaive patients with metastatic gastric cancer: a phase II multicentric trial. Br J Cancer 89: $997-1001$

Lim WT, Lim ST, Wong NS, Koo WH (2003) CPT-11 and cisplatin in the treatment of advanced gastric cancer in Asians. J Chemother 15: 400-405

Moiseyenko VM, Ajani JA, Tjulandin SA, Majlis A, Constenla M, Boni C, Anelli A, Yver AJ, Van Cutsem E (2005) Final results of a randomized controlled phase III trial (TAX 325) comparing docetaxel (T) combined with cisplatin (C) and 5-fluorouracil (F) to CF in patients (pts) with metastatic gastric adenocarcinoma (MGC). Proc Am Soc Clin Oncol 23: 308s (abstract no. 4002)

Ohtsu A, Shimada Y, Shirao K, Boku N, Hyodo I, Saito H, Yamamichi N, Miyata Y, Ikeda N, Yamamoto S, Fukuda H, Yoshida S (2003) Randomized phase III trial of fluorouracil alone versus fluorouracil plus cisplatin versus uracil and tegafur plus mitomycin in patients with unresectable, advanced gastric cancer: The Japan Clinical Oncology Group Study (JCOG9205). J Clin Oncol 21: 54-59

Pozzo C, Barone C, Szanto J, Padi E, Peschel C, Bukki J, Gorbunova V, Valvere V, Zaluski J, Biakhov M, Zuber E, Jacques C, Bugat R (2004) Irinotecan in combination with 5-fluorouracil and folinic acid or with cisplatin in patients with advanced gastric or esophageal-gastric junction adenocarcinoma: results of a randomized phase II study. Ann Oncol 15: $1773-1781$

Ridwelski K, Gebauer T, Fahlke J, Kroning H, Kettner E, Meyer F, Eichelmann K, Lippert H (2001) Combination chemotherapy with docetaxel and cisplatin for locally advanced and metastatic gastric cancer. Ann Oncol 12: $47-51$

Roth AD, Maibach R, Martinelli G, Fazio N, Aapro MS, Pagani O, Morant R, Borner MM, Herrmann R, Honegger H, Cavalli F, Alberto P, Castiglione 
M, Goldhirsch A (2000) Docetaxel (Taxotere)-cisplatin (TC): an effective drug combination in gastric carcinoma. Swiss Group for Clinical Cancer Research (SAKK), and the European Institute of Oncology (EIO). Ann Oncol 11: $301-306$

Shin HR, Jung KW, Won YJ, Park JG (2004) 2002 Annual Report of the Korea Central Cancer Registry: based on registered data from 139 hospitals. Cancer Res Treat 36: $103-114$

Simon R (1989) Optimal two-stage designs for phase II clinical trials. Control Clin Trials 10: $1-10$

Sulkes A, Smyth J, Sessa C, Dirix LY, Vermorken JB, Kaye S, Wanders J, Franklin H, LeBail N, Verweij J (1994) Docetaxel (Taxotere) in advanced gastric cancer: results of a phase II clinical trial. EORTC Early Clinical Trials Group. Br J Cancer 70: $380-383$

Therasse P, Arbuck SG, Eisenhauer EA, Wanders J, Kaplan RS, Rubinstein L, Verweij J, Van Glabbeke M, van Oosterom AT, Christian MC, Gwyther SG (2000) New guidelines to evaluate the response to treatment in solid tumors. European Organization for Research and Treatment of Cancer,
National Cancer Institute of the United States, National Cancer Institute of Canada. J Natl Cancer Inst 92: 205-216

Vanhoefer U, Rougier P, Wilke H, Ducreux MP, Lacave AJ, Van Cutsem E, Planker M, Santos JG, Piedbois P, Paillot B, Bodenstein H, Schmoll HJ, Bleiberg H, Nordlinger B, Couvreur ML, Baron B, Wils JA (2000) Final results of a randomized phase III trial of sequential high-dose methotrexate, fluorouracil, and doxorubicin versus etoposide, leucovorin, and fluorouracil versus infusional fluorouracil and cisplatin in advanced gastric cancer. A trial of the European Organization for Research and Treatment of Cancer Gastrointestinal Tract Cancer Cooperative Group. J Clin Oncol 18: 2648-2657

Webb A, Cunningham D, Scarffe JH, Harper P, Norman A, Joffe JK, Hughes M, Mansi J, Findlay M, Hill A, Oates J, Nicolson M, Hickish T, O’Brien M, Iveson T, Watson M, Underhill C, Wardley A, Meehan M (1997) Randomized trial comparing epirubicin, cisplatin, and fluorouracil versus fluorouracil, doxorubicin, and methotrexate in advanced esophagogastric cancer. J Clin Oncol 15: 261-267 